\title{
Editorial
}

\section{Riesgos de desinformación en tiempos de la pandemia de COVID-19}

Comunicación

número 42

Enero-junio

2020 | pp. 5-9

\section{Gabriel}

\section{Lotero-Echeverri}

Doctor en Comunicación

Docente investigador de

la Universidad Pontificia

Bolivariana, Medellín

gabrielj.lotero@upb.edu.co

\section{DOI: http://dx.doi.org/10.18566/comunica.n42.a01}

En este año 2020, la humanidad afronta una crisis inédita ante el impacto de la pandemia de la enfermedad por coronavirus (COVID-19), hallada en diciembre de 2019 en la ciudad china de Wuhan. A junio, 216 países reportan casos de contagio, según la Organización Mundial de la Salud (oms). Colombia, como muchos otros países, ha decretado un confinamiento preventivo para proteger a su población de un contagio masivo que colapse el sistema nacional de salud.

En este escenario, se ha acelerado el proceso de virtualización de muchas de las actividades cotidianas como el trabajo, los colegios, las universidades, la atención de las entidades públicas, el comercio, el entretenimiento y las comunicaciones interpersonales. En este contexto y por tratarse de la pandemia más mediática de la historia, la oms (2020a) ha reconocido la amenaza que representa la desinformación e incluso cuenta con una plataforma para responder los bulos y las cadenas de desinformación que pueden afectar la respuesta de las personas y las medidas de protección ante el virus.

Alrededor del mundo, investigadores y universidades concentran sus esfuerzos para sumar su aporte en la lucha contra la pandemia desde diferentes disciplinas. De igual forma, revistas especializadas de diferentes países y campos han orientado sus publicaciones para visibilizar este problema de salud pública, dada su naturaleza compleja y multidimensional.

Desde el campo de la comunicación y el periodismo, se han venido conociendo convocatorias orientadas específicamente a la investigación en este campo y también sobre los desafíos que representa la cobertura informativa de la pandemia para el ejercicio periodístico, con el propósito de aportar en esta coyuntura y, de manera específica, en la lucha contra la desinformación. En este sentido, se destacan los siguientes riesgos de la desinformación en época de pandemia. 


\section{Infodemia e infoxicación}

En la sociedad contemporánea, los ciudadanos del mundo configuran su infodieta en medio de una avalancha informativa que puede ocasionar una infoxicación (Cornellá, 2004), dada la dificultad de responder a la sobresaturación por volúmenes crecientes de información y datos. Pero, en época de pandemia, la oms (2020b) ha identificado la infodemia como una problemática global estructural, caracterizada por la desinformación en el campo de la medicina.

Además, los impactos de la infodemia en la salud de las personas se ven agravados por la resonancia propia de un ecosistema comunicativo en el cual la información es un recurso superabundante, si bien procede de todo tipo de fuentes. Esta condición se refuerza gracias a un modelo de comunicación de muchos a muchos (Castells, 2009), en el que se intercambian permanentemente los roles de consumidor y productor de contenidos, sin necesidad de intermediarios (Jenkins, 2008).

La figura del prosumidor se ve potenciada gracias a las tecnologías 2.0, a las plataformas de las redes sociales digitales, en las cuales la producción de contenidos está al alcance de cualquiera que disponga de un dispositivo conectado a internet. En medio de esta pandemia, miles de personas han sido víctimas de la desinformación y la manipulación; incluso muchos se han intoxicado por seguir recomendaciones tan extremas como ingerir cloro, porque así lo ha sugerido algún influenciador en las redes y le obedecen, aunque no se trate de un experto en el tema ni dicho remedio se base en algún estudio riguroso; asimismo, abundan los bulos relacionados con las vacunas. En la comprensión de este escenario, cobra valor la compilación Comunicación en el escenario digital: actualidad, retos y prospectivas, trabajo en el cual se encuentran investigaciones recientes, presentado por Bárbara Castillo-Abdul.

\section{Hiperconexión y dependencia}

En la sociedad contemporánea, el consumo de información ha vivido un proceso de transformación acelerado que ha cambiado la manera en la cual se accede y se comparte información (Fernández, 2018). Se produce un fenómeno de hiperconexión a internet a través de distintos dispositivos, especialmente desde los smartphones, por su movilidad y la versatilidad de sus aplicaciones, que responden a gran diversidad de usos y a la sensación de inmediatez. 
Por lo tanto, el smartphone se ha convertido en la pantalla más utilizada por una franja creciente de usuarios, especialmente en aquellos países que cuentan con un nivel alto de acceso a estos dispositivos. Según datos de MiNTIC (2020), a finales del año 2019, Colombia alcanzó una cifra de 6,7 millones de accesos a internet fijo que representan 13,8 por cada 100.000 habitantes. En ese mismo período, se registran 30,9 millones de accesos a internet móvil en el país que representan 61,3 por cada 100.000 habitantes. En diciembre de 2020, hay 66,28 millones de líneas de telefonía móvil que representan 131,6 líneas de telefonía móvil por cada 100 habitantes.

En este contexto, el tiempo destinado a las pantallas es creciente y surge la preocupación por cuántas horas al día de uso de redes sociales digitales, de uso de pantallas, podría representar una amenaza a la salud mental de una persona. Según la investigación de Díaz-López, Maquilón-Sánchez y MireteRuiz (2020), más del 60\% de los adolescentes utiliza las TIC sin supervisión y la tercera parte se sienten estresados si no pueden conectarse a internet. De acuerdo con CCAdicciones (2020), una persona puede consultar el celular unas 100 veces al día. El abuso del celular ocurre cuando se hace un uso problemático de estos dispositivos y se genera ansiedad o malestar por no poder utilizarlo, cuando se produce una necesidad permanente y representa un obstáculo para el normal desarrollo de otras actividades.

Según un estudio reciente realizado con una muestra española, en época de pandemia ha aumentado el uso del smartphone en un 38,3\%. La media ha pasado de 2 horas y 40 minutos al día a 3 horas y 24 minutos en la segunda semana de marzo (Smartme Analytics, 2020). De acuerdo con una investigación de Moral y Fernández (2019), una persona puede hacer un uso problemático del internet, según algunos factores de riesgo y situaciones de vulnerabilidad, y esta obsesión por estar conectados puede limitar otras actividades y ser un obstáculo para el trabajo, el estudio y las relaciones interpersonales.

La máxima "conectarse o perecer", de Negroponte, se ha actualizado. Además de los riesgos de abuso de las TIC, de la inmediatez propia de una hiperconexión, propia de la movilidad, y de un manejo del espacio que permite superar barreras y límites territoriales, también es necesario reflexionar sobre el impacto de estos usos en la vivencia de la dimensión temporal. Fernández (2019) reconoce que el tiempo de los smartphones es la aceleración propia de las interacciones sincrónicas en línea y su abundancia de estímulos. Pero en la era del smartphone se transforman prácticas cotidianas como caminar, en contraste con los tiempos lentos, propios de un paseo a pie, como diría Fernando González (2010). 
Pedro Luciano Colangelo analiza la dimensión temporal del ciberespacio en su artículo "Cibertiempo, o el régimen temporal de la modernidad comunicacional”.

\section{Redes sociales digitales y consumo de información a través de fuentes no verificadas}

El fenómeno de las noticias falsas y malintencionadas no es nuevo, pero se ha complejizado, de manera especial, en la llamada "sociedad de la información", en la cual la posverdad es una amenaza tan seria que sirve para explicar victorias electorales tan inciertas como el Brexit, el triunfo de un outsider como Trump o incluso el fracaso del plebiscito por la paz en Colombia (Lotero-Echeverri, Romero-Rodríguez \& Pérez-Rodríguez, 2018).

Estas campañas están relacionadas también con la propaganda negra. Para una mejor comprensión de esta perspectiva, el artículo "La exaltación del deseo en la propaganda militar de Colombia", del profesor Carlos Berrío, presenta un análisis de un caso destacado de propaganda oficial. La profesora Yeny Pulido expone una metodología para el análisis semiótico de campañas audiovisuales en su artículo "Colombia desde spots políticoelectorales televisivos para la Presidencia".

Ante la persistencia de las fake news y la facilidad de dispersión que estas han ganado en las plataformas de las redes sociales digitales, principalmente en Whatsapp, el desafío es lograr que las personas fortalezcan sus competencias mediáticas para identificar fuentes válidas, desconfiar ante los contenidos falsos y malintencionados, y pensar dos veces antes de compartir dichas cadenas maliciosas con sus contactos (Lotero-Echeverri, Romero-Rodríguez \& Pérez-Rodríguez, 2019).

Un usuario atento puede detectar señales del engaño si presta atención al formato de la información, verificar si incluye una autoría creíble, si cita fuentes de información adecuadas y sus enlaces funcionan, si dicha información está presente en otro medio de comunicación reconocido o si contiene errores ortográficos, como sugiere Javier Cifuentes-Faura en su artículo "Fake news durante la COVID-19: ¿Cómo detectarlas?".

Se debe buscar que la verdad sea tan atractiva como la mentira. Hoy eso no se ha logrado y es así como las rectificaciones no alcanzan la misma cobertura o resonancia que las cadenas de desinformación. 


\section{Referencias}

Castells, M. (2009). Comunicación y poder. Madrid: Editorial Alianza.

CCAdicciones (2020). 4 apps para saber si eres adicto al teléfono móvil. Disponible en: https: / / bit.ly/2BAnY1).

Cornellá, A. (2004). Infoxicación: Buscando un orden en la información. Barcelona: Infonomia.

Díaz-López, A.; Maquilón-Sánchez, J. \& Mirete-Ruiz, A. (2020). Uso desadaptativo de las TIC en adolescentes: perfiles, supervisión y estrés tecnológico. Comunicar, 64, pp. 29-38. Disponible en: .

Fernández, V. (2018). Comportamiento informacional: nuevos escenarios, nuevos desafíos. Páginas Aerb, 3, pp. 3-16. Disponible en: https:// doi.org/10.21747/21836671/pag8a1.

Fernández, A. (2019). Caminar en la era del smartphone. Revista Mexicana de Sociología, 81(4), 855-880. Disponible en: https:// doi.org/10.22201/iis.01882503p.2019.4.57979.

González, F. (2010). Viaje a pie. Medellín: Editorial Eafit.

Jenkins, H. (2008). Convergence culture. La cultura de la convergencia de los medios de comunicación. Buenos Aires: Paidós.

oms (2020a). Consejos para la población acerca de los rumores sobre el nuevo coronavirus (2019-nCoV). Disponible en: https:/ / bit.ly/3dGi2RL.

_-- (2020b). La desinformación frente a la medicina: hagamos frente a la "infodemia". Disponible en: https: / / bit.ly/31nwJXe.

Lotero-Echeverri, G.; Romero-Rodríguez, L. M. \& Pérez-Rodríguez, M. A. (2018). Fact-checking vs. Fake news: Periodismo de confirmación como recurso de la competencia mediática contra la desinformación. Index.comunicación, 8(2), pp. 295-316. Disponible en: http:// bit.ly/2Lp71LP.

_-_ (2019). Tendencias de las publicaciones especializadas en el campo de la educomunicación y alfabetización mediática en Latinoamérica. Interface (Botucatu), 23, pp. 1-17. Disponible en: https:// doi.org/10.1590/Interface.180193.

MINTIC (2020). Boletín trimestral de las TIC: Cifras cuarto trimestre de 2019. Disponible en: https:// bit.ly/3fxoucu.

Moral Jiménez, M. \& Fernández Domínguez, S. (2019). Uso problemático de internet en adolescentes españoles y su relación con autoestima e impulsividad. Avances en Psicología Latinoamericana, 37(1), pp. 103-119. Disponible en: https://doi.org/http:// dx.doi.org/10.12804/ revistas.urosario.edu.co/apl/a.5029.

Smartme Analytics (2020). Estudio del impacto del coronavirus en el uso del móvil. Disponible en: https:// bit.ly/38blXVI. 